\title{
P53 Codon 72 (Arg72Pro) Polymorphism and Prostate Cancer Risk: Association between Disease Onset and Proline Genotype
}

\author{
Anja Rogler ${ }^{a}$ Michael Rogenhofer ${ }^{c}$ Albert Borchardt ${ }^{d}$ Jens-Claudio Lunz ${ }^{e}$ \\ Antje Knoell $^{b}$ Ferdinand Hofstaedter ${ }^{f} \quad$ Andrea Tannapfel $^{\text {h }} \quad$ Wolf Wieland $^{g}$ \\ Arndt Hartmann ${ }^{a}$ Robert Stoehra \\ Institutes of a Pathology and ${ }^{\mathrm{b}} \mathrm{Clinical}$ and Molecular Virology, and ${ }^{\mathrm{C}}$ Department of Urology, University Hospital \\ Erlangen, and dUrological Joint Practice, Medical Center Roethelheimpark, Erlangen, ${ }^{\mathrm{e}}$ Group Practice for General \\ Medicine, Siegenburg, ${ }^{\mathrm{f}}$ Institute of Pathology, and ${ }^{9}$ Department of Urology, Caritas St. Josef Medical Center, \\ University of Regensburg, Regensburg, and ${ }^{\mathrm{h}}$ Institute of Pathology, Ruhr University Bochum, Bochum, Germany
}

\section{Key Words}

p53 - Prostate cancer · Single-nucleotide polymorphism • Restriction fragment length polymorphism

\begin{abstract}
The tumor suppressor gene p53 plays an important role in the stress response of the cell and is mutated in $50 \%$ of all human tumors. The p53 Arg72Pro single-nucleotide polymorphism (SNP) was found to be associated with an increased risk of various malignancies. Biochemical and biological differences between the 2 polymorphic variants of wild-type P53 might lead to distinct susceptibility to HPVand non-HPV-induced tumors. For prostate cancer, only limited data are available, especially in the Caucasian population. Therefore, we determined the distribution of the Arg72Pro SNP in a Caucasian case-control study including 118 prostate cancer patients and 194 male controls without any malignancy using restriction fragment length polymorphism analysis. A subset of 33 tumors was tested for HPV infection, and no HPV DNA was found. Cases and controls showed similar distributions of alleles in the SNP $(p=0.720)$. Regarding the onset of the disease, patients diagnosed at
\end{abstract}

\section{KARGER}

Fax +41613061234 E-Mail karger@karger.ch www.karger.com

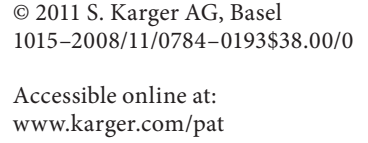

$\leq 60$ years of age and older patients ( $>60$ years of age) showed a significant difference in genotype distribution $(p=0.035)$; there was also an increased occurrence of risk allele Pro72 in cases aged $\leq 60$ years $(p=0.045)$. A subset of 64 prostate tumors was stained immunohistochemically for P53. 5 of 64 prostate tumors (7.8\%) were positive for P53 expression, indicating integrity of the protein in the majority of cases. Genotype distribution showed no association with the Gleason score or additional histopathological characteristics. This study shows that the overall risk of prostate cancer was not associated with Arg72Pro SNP and HPV infection in our cohort. However, disease onset might be modulated by the p53 Pro72 allele, suggesting an important role of apoptosis regulation in prostate carcinogenesis.

Copyright $\odot 2011$ S. Karger AG, Basel

\section{Introduction}

Prostate cancer (PCa) is the most common cancer type in men and the 4 th most common cancer type in Europe. Demographic development and the introduction of PSA screening will lead to an increasing incidence in the fu-

Dr. Robert Stoehr

Institute of Pathology, University Hospital Erlangen

Universitätsstrasse 22

DE-91054 Erlangen (Germany)

Tel. +4991318526088, E-Mail robert.stoehr@uk-erlangen.de 
ture. In 2008, there were 382,300 new PCa cases and 89,300 cases of PCa-related deaths $(9.3 \%$ of all cancerrelated causes of death in men) reported in Europe [1]. PCa has a 5-year survival rate of $87 \%$ but often leads to severe restriction of men's life quality and high expenses for the health care system [2]. Therefore, the search for inherited cancer susceptibility factors, such as single-nucleotide polymorphisms (SNPs), is a major focus of epidemiologic cancer studies. Analyses of SNPs in a variety of genes have revealed a correlation between specific allele variants and cancer predisposition.

The tumor suppressor gene p53 plays an important role in the stress response of the cell. In unstressed cells only low levels of P53 are present. P53 is ubiquitinated via MDM2 and ARF-BP1, which leads to degradation in the proteasome. In cases of cellular stress, like DNA damage, hypoxia, or oncogene activation, for example, the p53 pathway is upregulated (via p21, PUMA, and BAX, among others) and this results in cellular stress responses such as apoptosis and DNA repair or cell cycle and growth arrest [3]. p53 is mutated in 50\% of all human tumors, whereas $90 \%$ of those mutations lead to a decreased ability to bind DNA targets and hence to disability of appropriate stress-responses $[4,5]$. Mutations and other alterations in p53 lead to increased proliferation, cell growth, and incomplete DNA-repair, which finally results in development of malignancies. For PCa very discrepant frequencies for $\mathrm{p} 53$ mutations are reported, ranging from 3 to $42 \%$. Among other reasons, this might be due to considerable methodological heterogeneity [6].

A well-studied single base pair variant of p53 in exon 4 , codon 72 represents a genomic polymorphism and not a mutation. This p53 Arg72Pro SNP encodes for 2 wildtype variants of P53, either arginine (Arg72) or proline (Pro72). A single-base exchange from CGC to CCC causes the alteration of amino acid residue 72 [7]. Both wild-type forms have the same ability to bind DNA, but they show different potentials to bind components of the transcriptional machinery, activate transcription, induce apoptosis, and repress the malignant transformation of cells [8]. The Arg72 form induces apoptosis markedly better due to enhanced mitochondrial trafficking of this isoform [9].

The association between the $\mathrm{p} 53$ codon 72 polymorphism and tumor formation has been extensively studied in various malignancies [10]. In addition, the 2 polymorphic variants might lead to a different susceptibility to tumor induction by human papillomavirus (HPV). In non-HPV-induced tumors, Pro72 is assumed to be the risk allele for the development of cancer. However, in HPV-induced malignancies, the Arg72 especially leads to tumor formation as the oncogenic HPV E6 protein preferentially targets Arg72 for ubiquitination-mediated degradation $[11,12]$.

For PCa only limited data are available about the association between the p53 Arg72Pro polymorphism, $\mathrm{HPV}$ infection, and tumor growth, especially in the Caucasian population. Generally, only 2 studies showed a significant association between this SNP and PCa risk, but they had conflicting results. While Henner et al. [13] reported a reduced PCa risk of the Pro72 variant in Caucasians, Wu et al. [14] found an increased risk for the development of metastasis in Taiwanese PCa patients for the Pro72 isoform [15]. However, in the Caucasian study, the distribution of genotypes for the control group was not consistent with Hardy-Weinberg equilibrium.

Due to these controversial results and a lack of reliable data about the genotype distribution in this p53 SNP in the Caucasian population, we analyzed the distribution of the Arg72Pro SNP in Caucasian PCa patients and in a healthy control group. Because of the possible association between HPV infection and an increased tumor risk modulated by the $\mathrm{p} 53$ Arg72Pro SNP, we also determined the HPV status in a subset of the tumors.

\section{Subjects and Methods}

\section{Samples}

Overall, 118 PCa patients, all of whom underwent radical prostatectomy, were included in our study. Formalin-fixed and paraffin-embedded tissue samples from these patients were available from the prostatectomy specimens. For comparison, 194 blood samples from a male control group of patients without any malignancy were investigated

All tumors were diagnosed according to the 2004 WHO classification of prostate tumors [16] and staged according the TNM system [17]. The clinicopathological characteristics of the study participants are shown in table 1. IRB approval was obtained for this study.

Tissue Microdissection and DNA Isolation

DNA was extracted from manually microdissected normal prostate tissue or peripheral blood using a High Pure PCR Template Preparation Kit (Roche $\mathrm{GmbH}$, Mannheim, Germany) according to manufacturer's instructions.

\section{P53 Arg72Pro SNP Analysis}

SNP analysis was carried out by restriction fragment length polymorphism analysis (RFLP) of the polymorphic region in exon 4 which contains a Bst UI recognition site (5'-CG $\mathbf{V}$ CG-3') in the presence of the G-allele (Arg72) [18]. The presence of the Arg72 allele resulted in digestion of the PCR product (196 bp = $113+83 \mathrm{bp}$ ), whereas PCR products containing the C-allele (Pro72) remained unaffected. 
Table 1. Characteristics of study participants

\begin{tabular}{lcc}
\hline & Cases $(\mathrm{n}=118)$ & Controls $(\mathrm{n}=194)$ \\
\hline Age, years & & 69 \\
$\quad$ Median & 65 & $67.3 \pm 10.6$ \\
Mean \pm years of age & $64.2 \pm 6.0$ & $34-88$ \\
$\quad$ Range & $46-74$ & \\
Stage & & \\
$\quad$ Organ-confined & 57 & \\
$\quad$ Non-organ-confined & 55 & \\
No data available & 6 & \\
Gleason score & & \\
$\quad$ Median & 7 & \\
Range & $3-10$ & \\
Gleason sum & 3 \\
3-4 & 84 \\
5-7 & 22 \\
8-10 & 9 & \\
No data available &
\end{tabular}

Amplification of Region Variants and RFLP Analysis

The SNP region was amplified by PCR using primers (sense: 5'-TTG CCG TCC CAA GCA ATG-3'; antisense: 5'-GGG AAG GGA CAG AAG ATG-3') obtained from Metabion (Martinsried, Germany) in a total volume of $25 \mu \mathrm{l}$ containing approximately 100 ng DNA, $0.2 \mathrm{~mm}$ dNTP (Promega, Mannheim, Germany), $0.18 \mu \mathrm{M}$ primers, and $0.0025 \mathrm{U} / \mu \mathrm{l}$ GoTaq (Promega). The thermal cycling conditions were as follows: initial denaturation for $3 \mathrm{~min}$ at $95^{\circ} \mathrm{C}, 35$ cycles of denaturation at $95^{\circ} \mathrm{C}$ for $1 \mathrm{~min}$, annealing at $61^{\circ} \mathrm{C}$ for $1 \mathrm{~min}$, elongation at $72^{\circ} \mathrm{C}$ for $1 \mathrm{~min}$, and final primer extension at $72^{\circ} \mathrm{C}$ for $10 \mathrm{~min}$. Gradient PCR was used for optimization of the cycling conditions.

PCR products were incubated for $6 \mathrm{~h}$ with $5 \mathrm{U}$ Bst UI (New England Biolabs, Frankfurt/Main, Germany) at $60^{\circ} \mathrm{C}$ in a total volume of $30 \mu \mathrm{l}$ to ensure complete digestion. Restriction fragments were separated by electrophoresis using $2 \%$ agarose gels and visualized under ultraviolet light using $0.05 \%$ ethidium bromide.

\section{Sequencing Analysis}

Twelve randomly selected cases were sequenced to verify the RFLP results. After amplification, PCR products were purified using a Qiagene Dye Ex 2.0 TM Spin Kit according to the manufacturer's instructions. Sequence analysis was performed with the primers mentioned above using an Applied Biosystems Big Dye Terminator v1.1 Cycle Sequencing Kit and an Applied Biosystems ABI PRISM 310 Genetic Analyzer.

\section{HPV PCR Analysis of Prostate Tumors}

Tumor cells were microdissected and DNA was extracted using a High Pure PCR Template Preparation Kit (Roche) according to the manufacturer's instructions. HPV DNA testing was performed by PCR as described by Petry et al. [19].

P53 Codon 72 (Arg72Pro) Polymorphism and PCa Risk
P53 Immunohistochemistry

Archival formalin-fixed, paraffin-embedded prostate tumors from 64 cases were assembled for tissue microarray (TMA). Three-micrometer sections were stained overnight with a P53 mouse monoclonal antibody (clone DO-7, dilution 1:50 with albumin; DakoCytomation, Hamburg, Germany). P53 staining was detected using a ZytoChem Fast AP One-Step Polymer Kit (Zytomed Sytems, Berlin, Germany) according to the manufacturer's instructions. As a positive control, a human peritoneal carcinosis specimen was stained in parallel to the TMA sections. Immunohistochemical staining was evaluated by an experienced surgical pathologist (A.H.) in a blinded fashion. Tumors with more than $10 \%$ nuclear staining for P53 were scored as positive.

Statistical Analysis

To test if the genotype distribution followed Hardy-Weinberg equilibrium, the public software at http://ihg.gsf.de/cgi-bin/hw/ hwa1.pl was used. $\chi^{2}$ statistics (2-sided exact significance) were used to evaluate case-control differences in the distribution of genotypes and to analyze associations between genotypes and age or histopathological characteristics. To determine the distribution of the risk allele versus the nonrisk allele, Fisher's exact test (2-sided exact significance) was used. $\mathrm{p}<0.05$ was considered statistically significant.

\section{Results}

Verification of the RFLP analysis by sequencing showed $100 \%$ concordance between the 2 methods. All results derived from the RFLP analysis could be confirmed by sequencing. Representative examples of genotyping are shown in figure 1 , and representative sequencing results are shown in figure 2.

The genotype distribution in our cohorts followed Hardy-Weinberg equilibrium in cases $(p=0.641)$ and controls $(\mathrm{p}=0.575)$. The genotype distribution between cases and controls did not differ significantly $(\mathrm{p}=0.720)$ (table 2; fig. 3). There was also no correlation between the SNP distribution and the Gleason score ( $\mathrm{p}=0.718$; table 2 ) or stage ( $p=0.160$; table 2$)$ of the tumors.

To analyze a possible age-dependent distribution of the p53 Arg72Pro SNP, we divided PCa cases into 2 groups: one group consisted of younger patients $(\leq 60$ years) and the second group consisted of patients with an age of $>60$ years at disease onset. Regarding the onset of the disease, there was a significant difference in genotype distribution between both groups $(\mathrm{p}=0.035)$, with an increased occurrence of the risk allele Pro72 in the younger patient group $(\mathrm{p}=0.045)$ (table 2 ; fig. $4 \mathrm{a}, \mathrm{b})$. This agedependent distribution was not detectable in the control group ( $p=0.715)$. All results of the distribution of allelic variants between cases and controls and between relevant tumor/patient characteristics are shown in table 2.

Pathobiology 2011;78:193-200 
Fig. 1. Representative example for P53 Arg72Pro SNP RFLP analysis. Lanes 1 and 18 = DNA standard; lanes 2-13 = samples; lane $14=$ positive control; lane $16=$ water control; lanes 15 and $17=$ empty.
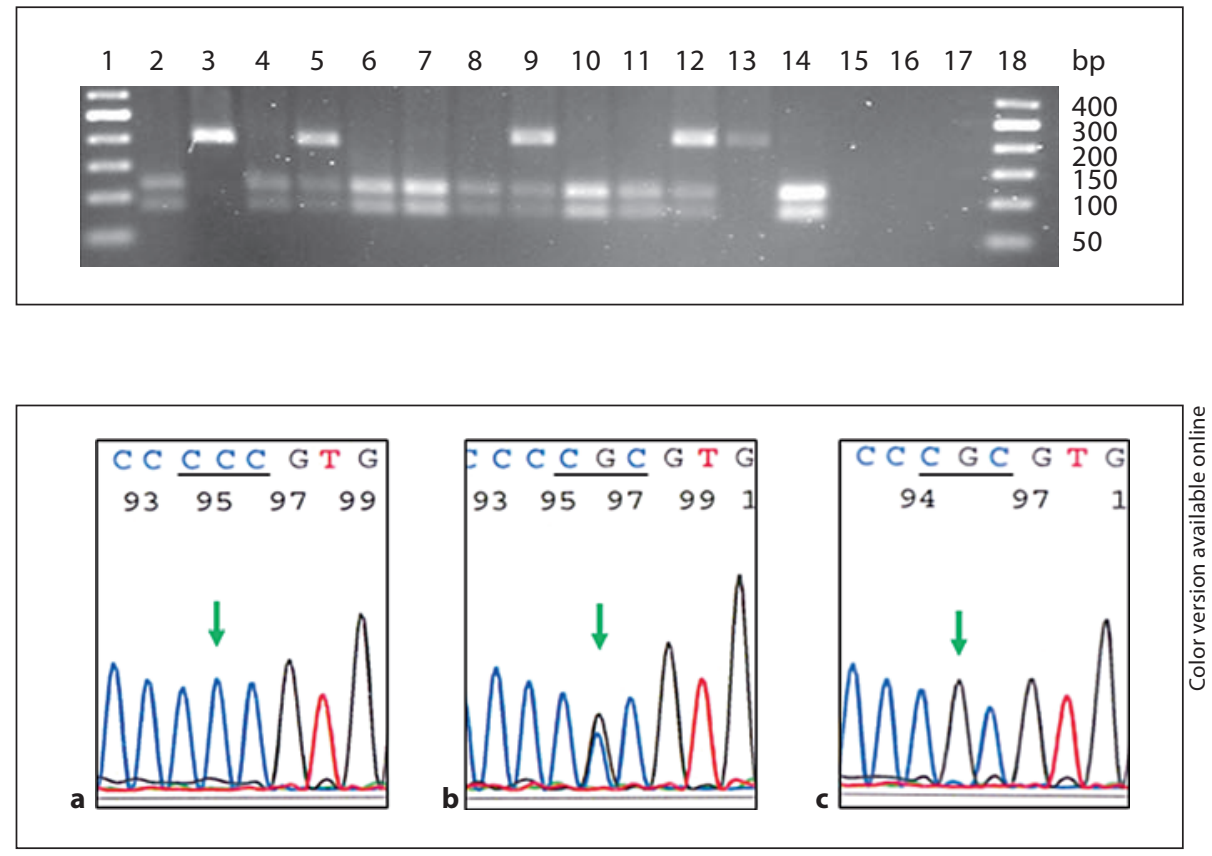

Fig. 2. Representative sequencing results for verification of the RFLP analysis. There was a $100 \%$ concordance between both methods. a Homozygous Pro72, RFLP lane 2. b Heterozygous variant, RFLP lane 5. c Homozygous Arg72, RFLP lane 7.
To determine the integrity of the P53 protein in the tumors, a subset of 64 tumor specimens were analyzed immunohistochemically. Only 5/64 (7.8\%) cases showed positivity for $\mathrm{P} 53$, indicating an altered $\mathrm{p} 53$ protein in only a small number of cases. Representative examples of P53 immunohistochemistry are shown in figure 5.

For 33 tumor samples, sufficient amounts of tumor tissue could be obtained by microdissection to isolate DNA for HPV PCR. All 33 HPV-tested PCa specimens were found to be negative for HPV DNA by a PCR protocol covering a wide variety of HPV types, including the relevant high-risk and low-risk oncogenic HPV types.

\section{Discussion}

The tumor suppressor gene $\mathrm{p} 53$ plays a major role in the development of human malignancies. The polymorphic variant of p53 at codon 72 has been found to be associated with cancer susceptibility in various tumor entities, but only few studies have investigated its effect on PCa risk [11].

In our study with 118 Caucasian PCa cases and 194 healthy controls we found that the overall risk of PCa was not associated with the p53 Arg72Pro polymorphism. To date, only 3 studies have reported a statistically significant association between genotype distribution and disease risk for PCa: one study in a Taiwanese cohort [14], a

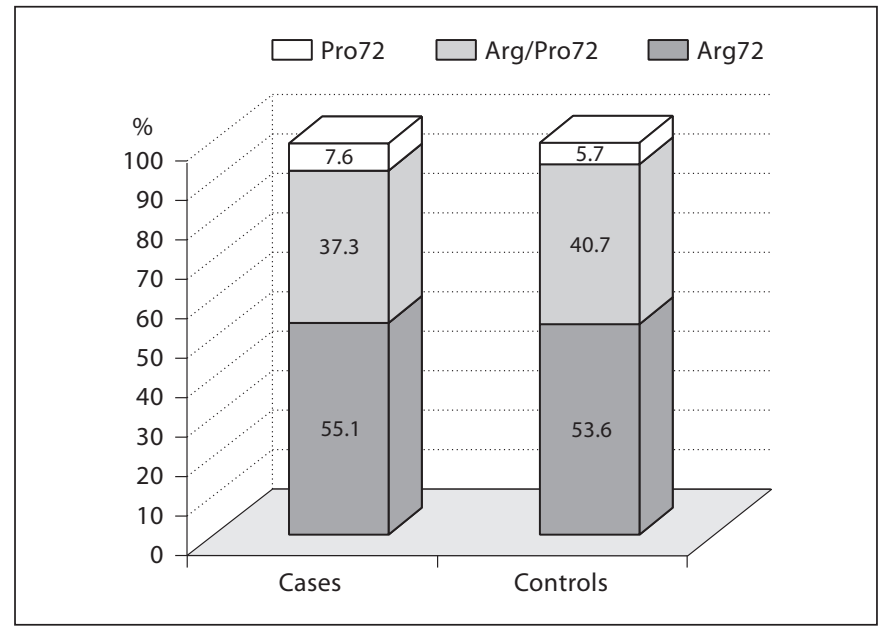

Fig. 3. Graphic illustration of the distribution of p53 Arg72Pro SNP genotypes between controls and cases. No significant difference was found $(\mathrm{p}=0.720)$.

second study in a Caucasian cohort [13], and a third study in a patient cohort of individuals of African descent [20]. However, all 3 studies showed controversial results and the Caucasian control group was not consistent with Hardy-Weinberg equilibrium, advising caution in the interpretation of these results. Our study showed no association between the p53 codon 72 SNP and PCa risk in a German PCa cohort, which is in line with 3 other non- 

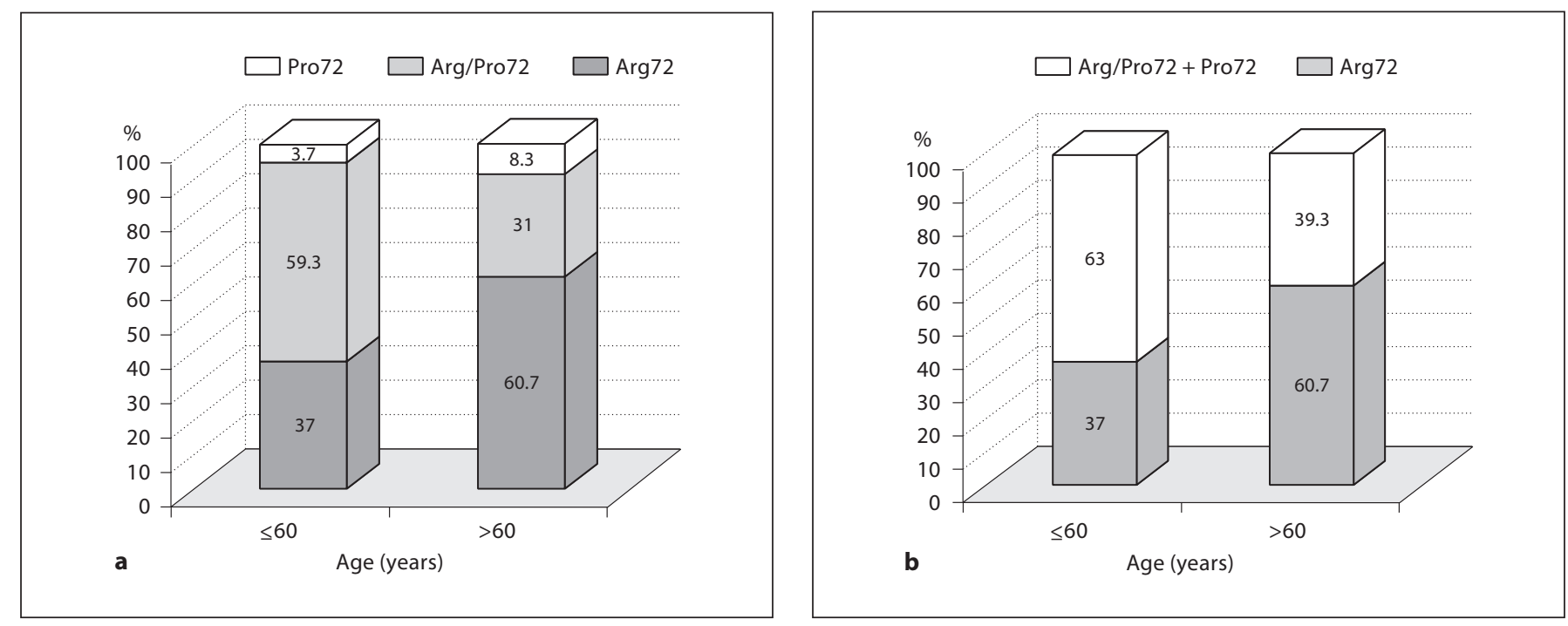

Fig. 4. Age-dependent distribution of Arg72Pro SNP in tumor patients. a A significant difference was found between patients aged $>60$ or $\leq 60$ years $(p=0.035)$; $\mathbf{b}$ younger patients showed increased incidences of the Pro72 risk allele $(\mathrm{p}=0.045)$.
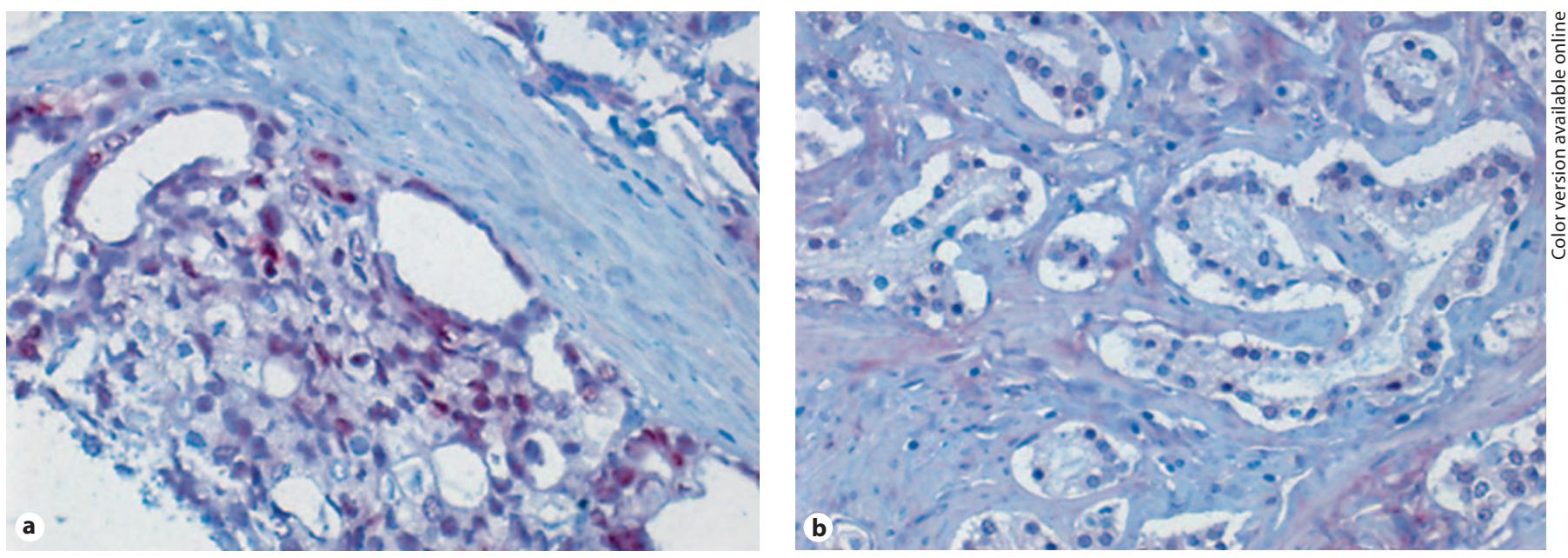

Fig. 5. Representative examples for positive and negative P53 immunohistochemistry. a PCa specimen [pT3a, G3, Gleason score $7(4+3)$, with $15 \%$ of the cells showing nuclear staining]. Magnification $\times 400$. b Prostate tumor [pT3b, G2, Gleason score $6(4+2)$ negative for P53]. Magnification $\times 400$.

Caucasian studies [21-23]. To ensure that our control cohort was representative of Caucasians in terms of the genotype distribution pattern, we compared our data with 2 other Caucasian male control groups $[24,25]$ and found very similar results (data not shown), strengthening the validity of our control group and of our results.

However, our results provide evidence that disease onset might be modulated by the Pro72 allele. In our PCa cohort, patients aged $\leq 60$ years at the time of diagnosis showed a significant increase in the risk allele, suggesting the Pro72 variant as an inherited risk factor for earlier disease onset. This age-dependent shifting of the allele distribution was not seen in the control group. There is an ongoing discussion about the definition of early-onset PCa [26]. The age mostly used for the definition of early disease onset in the literature ranges from 55 to 65 years 
Table 2. Distribution of allelic variants between cases and controls and between relevant tumor/patient characteristics

\begin{tabular}{|c|c|c|c|c|c|}
\hline \multirow[t]{2}{*}{ Genotype } & \multirow[t]{2}{*}{ Cases } & \multirow[t]{2}{*}{ Controls } & \multicolumn{3}{|c|}{ Comparison } \\
\hline & & & $\mathrm{p}$ & OR & $95 \%$ CI \\
\hline Arg & $65(55.1)$ & $104(53.6)$ & & & \\
\hline Hetero & $44(37.3)$ & 79 (40.7) & 0.720 & & \\
\hline Pro & $9(7.6)$ & $11(5.7)$ & & & \\
\hline Arg & $65(55.1)$ & $104(53.6)$ & 0.816 & 0.942 & $0.595-1.492$ \\
\hline \multirow[t]{2}{*}{ Hetero + Pro } & $53(44.9)$ & $90(46.4)$ & & & \\
\hline & Cases Gleason sum $<7$ & Cases Gleason sum $\geq 7$ & & & \\
\hline Arg & $30(61.2)$ & $32(53.3)$ & & & \\
\hline Hetero & $16(32.7)$ & $23(38.3)$ & 0.718 & & \\
\hline Pro & $3(6.1)$ & $5(8.3)$ & & & \\
\hline Arg & $30(61.2)$ & $32(53.3)$ & 0.442 & 1.382 & $0.642-2.973$ \\
\hline \multirow{2}{*}{ Hetero + Pro } & $19(38.8)$ & $28(46.6)$ & & & \\
\hline & Organ-confined tumors & \multicolumn{2}{|l|}{ Non-organ-confined tumors } & & \\
\hline Arg & $31(54.4)$ & $33(60)$ & & & \\
\hline Hetero & $24(41.2)$ & $16(29.1)$ & 0.160 & & \\
\hline Pro & $2(3.5)$ & $6(10.9)$ & & & \\
\hline Arg & $31(54.4)$ & $33(60)$ & 0.572 & 0.795 & $0.375-1.683$ \\
\hline \multirow[t]{2}{*}{ Hetero + Pro } & $26(45.6)$ & $22(40)$ & & & \\
\hline & Cases aged $\leq 60$ & Cases aged $>60$ & & & \\
\hline Arg & $10(37)$ & $51(60.7)$ & & & \\
\hline Hetero & $16(59.3)$ & $26(31)$ & 0.035 & & \\
\hline Pro & $1(3.7)$ & $7(8.3)$ & & & \\
\hline Arg & $10(37)$ & $51(60.7)$ & 0.045 & 0.381 & $0.155-0.932$ \\
\hline Hetero + Pro & $17(63)$ & $33(39.3)$ & & & \\
\hline
\end{tabular}

Results are patient numbers with percentages in parentheses.

$[27,28]$; for sporadic cancer the age at diagnosis is normally used equivalently to disease onset, which might imply a little bias. Due to a relatively low number of cases $<55$ years of age at time of diagnosis in our unselected patient cohort, we chose the mean value of the age range widely used in the literature as the cut off for our analysis. Nevertheless, a larger cohort of patients with early disease onset (e.g. $<50$ years) should be investigated to verify our results showing an age-dependent genotype distribution of this polymorphism.

Our results suggest that aberrant apoptosis regulation might play an important role in prostate carcinogenesis in younger patients. Indeed, PCa cells are able to develop various strategies to block apoptosis during progression from normal epithelial cells to PCa [29]. The malignant transformation of prostatic cells is favored by disruption of the balance between the proliferation and apoptosis of prostatic epithelial cells, and P53 is an important factor in maintaining this balance [30]. The molecular principles of impaired apoptosis by the Pro72 variant are still not fully understood. Recently, it was shown that there are different levels of transcription of P53-regulated genes by the p53 codon 72 SNP [31]. Interestingly, most of the genes involved in apoptosis which were found to be differentially expressed depending on the p53 variant were expressed at much lower levels in cells with the Pro72 variant compared to the Arg72 isoform. With a constant lower expression of members of the apoptosis pathway in 
cells with the P53 Pro72 variant, one might speculate that there is a higher susceptibility to an inadequate apoptotic response to cellular damage and an earlier onset of a malignancy could be explainable.

To further stress the possible importance of the p53 codon 72 SNP in PCa, we wanted to get some information on the integrity of the protein. Immunohistochemical staining revealed a low rate $(7.8 \%)$ of P53 nuclear accumulation in the tumors, which indicated a minor role of P53 alterations in our cohort. This is in line with several previously published studies [32-34]. The high number of P53-negative tumors, hence, strengthens the plausibility of investigating SNPs in $\mathrm{p} 53$ as predictive and progressive markers in PCa.

HPV infection is discussed controversially as a risk factor for PCa. Reported frequencies of HPV infections in PCa patients vary from 2 to 54\% [35]. Because of the known increased cancer risk for the combination of HPV infection and the homozygous Arg72 genotype in several malignancies, we also analyzed tumor tissue of a subset of our PCa cohort for HPV DNA. We could not find HPV DNA in these tumors, suggesting that HPV infection plays no major role in prostate carcinogenesis; this is in line with previously published studies [36, 37].

In summary, our case-control study revealed no evidence of an association between the P53 Arg72Pro polymorphism and an increased overall risk for PCa or of an association between this polymorphism and histopathological characteristics of the tumor. However, our results raise the possibility that the Pro72 variant is an inherited susceptibility marker for early disease onset in PCa.

\section{Acknowledgements}

We want to thank Claudia Knoll and Yvonne Sauermann for their excellent technical assistance.

\title{
References
}

$\longrightarrow$ Ferlay J, Parkin DM, Steliarova-Foucher E: Estimates of cancer and mortality in Europe in 2008. Eur J Cancer 2010;46:765-781.

2 RKI and GEKID: Cancer in Germany 2005/2006: Incidences and Trends 05/06, pp 72-75. http://www.rki.de/nn_1219822/EN/ Content/Health_Reporting/GBEDownloadsB $/$ KID2010,templateId=raw, property= publicationFile.pdf/KID2010.pdf.

-3 Brooks CL, Gu W: p53 ubiquitination: Mdm2 and beyond. Mol Cell 2006;21:307-315.

4 Meek DW: Tumor suppression by p53: a role for the DNA damage response? Nat Rev Cancer 2009;9:714-723.

5 Levine AJ: p53, the cellular gatekeeper for growth and division. Cell 1997;88:323-331.

-6 Agell L, Hernandez S, de Muga S, Lorente JA, Juanpere N, Esgueva R, Serrano S, Gelabert A, Lloreta J: KLF6 and TP53 mutations are a rare event in prostate cancer: distinguishing between Taq polymerase artifacts and true mutations. Mod Pathol 2008;21:1470-1478.

7 Ara S, Lee PS, Hansen MF, Saya H: Codon 72 polymorphism of the TP53 gene. Nucleic Acids Res 1990;18:4961.

${ }_{8}$ Thomas M, Kalita A, Labrecque S, Pim D, Banks L, Matlashewski G: Two polymorphic variants of wild-type p53 differ biochemically and biologically. Mol Cell Biol 1999;19: 1092-1100.

-9 Murphy ME, Leu JI, George DL: p53 moves to mitochondria: a turn on the path to apoptosis. Cell Cycle 2004;3:836-839.

10 Murphy ME: Polymorphic variants in the p53 pathway. Cell Death Differ 2006;13:916920.

P53 Codon 72 (Arg72Pro) Polymorphism and PCa Risk
11 Whibley C, Pharoa PDP, Hollstein M: p53 polymorphisms: cancer implications. Nat Rev Cancer 2009;9:95-107.

12 Storey A, Thomas M, Kalita A, Harwood C, Gardiol D, Mantovani F, Breuer J, Leigh IM, Matlashewski G, Banks L: Role of a p53 polymorphism in the development of human papilloma virus-associated cancer. Nature 1998;393:229-234.

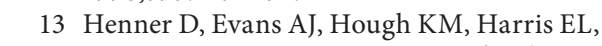
Lowe BA, Beer TM: Association of codon 72 polymorphism of p53 with lower prostate cancer risk. Prostate 2001;49:263-266.

$\checkmark 14$ Wu HC, Chang CH, Chen HY, Tsai FJ, Tsai JJP, Chen WC: p53 gene codon 72 polymorphism but not tumor necrosis factor- $\alpha$ gene is associated with prostate cancer. Urol Int 2004;73:41-46.

15 Zhu Y, Wang J, He Q, Zhang JQ: Association of $\mathrm{p} 53$ codon 72 polymorphism with prostate cancer: a meta-analysis. Mol Biol Rep 2011; 38:1603-1607.

16 Epstein JI, Algaba F, Allsbrook WC, Bastacky S, Boccon-Gibod L, De Marzo AM, Egevad L, Furusato M, Hamper UM, Helpap B, Humphrey PA, Iczkowski KA, Lopez-Beltran A, Montironi R, Rubin MA, Sakr WA, Samaratunga H, Parkin DM: Tumours of the prostate; in Eble JN, Sauter G, Epstein JI, Sesterhenn IA (eds): World Health Organization Classification of Tumours: Pathology and Genetics of Tumours of the Urinary System and Male Genital Organs. Lyon, IARC, 2004, pp 159-216.

17 Sobin LH, Wittekind C: TNM classification of malignant tumors. New York, Wiley, 2002.
18 Faur N, Araud L, Laroche-Clary A, Kanno J, Toutain J, Yamori T, Robert J, Le Morvan V: The association between the T309G polymorphism of the MDM2 gene and sensitivity to anticancer drug is dependent on the p53 mutational status in cellular models. $\mathrm{Br} \mathrm{J}$ Cancer 2009;101:350-356.

19 Petry KU, Menton S, Menton M, van LoenenFrosch F, de Carvalho Gomes H, Holz B, Schopp B, Garbrecht-Buettner S, Dvies P, Boehmer G, van den Akker E, Iftner T: Inclusion of HPV testing in routine cervical cancer screening for women above 29 years in Germany: results for 8,466 patients. Br J Cancer 2003;88:1570-1577.

20 Ricks-Santi L, Mason T, Apprey V, Ahaghotu C, McLauchlin A, et al: p53 Pro72Arg polymorphism and prostate cancer in men of African descent. Prostate, 2010;70:1739-1745.

21 Hirata H, Hinoda Y, Kikuno N, Kawamoto K, Dahiya AV, Suehiro Y, Tanaka Y, Dahiya $\mathrm{R}$ : CXCL12 G801A polymorphism is a risk factor for sporadic prostate cancer susceptibility. Clin Cancer Res 2007;13:5056-5062.

22 Huang SP, Wu WJ, Chang WS, Wu MT, Chen YY, Chen YJ, Yu CC, Wu TT, Lee YH, Huang JK, Huang CH: p53 codon 72 and p21 codon 31 polymorphisms in prostate cancer. Cancer Epidemiol Biomarkers Prev 2004;13: 2217-2224

-23 Leiros GJ, Galliano SR, Sember ME, Kahn T, Schwarz E, Eiguchi K: Detection of human papillomavirus DNA and $\mathrm{p} 53$ codon 72 polymorphism in prostate carcinomas of patients from Argentina. BMC Urol 2005;5:15.

\author{
and Pa Risk
}

Pathobiology 2011;78:193-200 
24 Koushik A, Tranah GJ, Ma J, Stampfer MJ, Sesso HD, Fuchs CS, Giovannucci EL, Hunter DJ: p53 Arg72Pro polymorphism and risk of colorectal adenoma and cancer. Int J Cancer 2006;119:1836-1868.

-25 Tornesello ML, Duraturo ML, Guida V, Losito S, Botti G, Pilotti S, Stefanon B, De Palo G, Buonaguro L, Buonaguro FM: Analysis of TP53 codon 72 polymorphism in HPV-positive and HPV-negative penile carcinoma. Cancer Lett 2008;269:159-164.

-26 Hughes L, Giri N: Genetic polymorphisms and early-onset prostate cancer: a real potential to personalize prostate cancer screening? Future Oncol 2009;5:923-926.

-27 Agalliu I, Karlins E, Kwon EM, Iwasaki LM, Diamond A, Ostrander EA, Stanford JL: Rare germline mutations in the BRCA2 gene are associated with early-onset prostate cancer. Br J Cancer 2007;97:826-831.
28 Koutros S, Schumacher FR, Hayes RB, Huang WY, Albanes D, Canzian F, Chanock SJ, Crawford ED, Diver WR, Feigelson HS, Giovanucci E, Haiman CA, Henderson BE, Hunter DJ, Kaaks R, Kolonel LN, Kraft P, Le Marchand L, Riboli E, Siddiq A, Stampfer MJ, Stram DO, Thomas G, Travis RC, Thun MJ, Yeager M, Berndt SI: Pooled analysis of phosphatidylinositol 3-kinase pathway variants and risk of prostate cancer. Cancer Res 2010;70:2389-2396.

29 Gurumurthy S, Vasudevan KM, Rangnekar VM: Regulation of apoptosis in prostate can cer. Cancer Metastasis Rev 2001;20:225-243.

30 Collavin L, Lunardi A, Del Sal G: P53-family protein and their regulators: hubs and spokes in tumor suppression. Cell Death Differ 2010;17:901-911.

-31 Jeong BS, Hu W, Belyi V, Rabadan R, Levine AJ: Differential levels of transcription of p53 regulated genes by the arginine/proline polymorphisms: p53 with arginine at codon 72 favors apoptosis. FASEB J 2010;24:13471353.

>32 Brooks JD, Bova GS, Ewing CM, Piantadosi S, Carter BS, Robinson JC, Epstein JI, Isaacs WB: An uncertain role for p53 gene alterations in human prostate cancers. Cancer Res 1996;56:3814-3822.
3 Hughes C, Murphy A, Martin C, Sheils O, O'Leary J: Molecular pathology of prostate cancer. J Clin Pathol 2005;58:673-684.

34 Massenkeil G, Oberhuber H, Hailemariam S, Sulser T, Diener PA, Bannwart F, Schafer $\mathrm{R}$, Schwarte-Waldhoff I: P53 mutations and loss of heterozygosity on chromosome $8 \mathrm{p}$, $16 \mathrm{q}, 17 \mathrm{p}$ and $18 \mathrm{q}$ are confined to advanced prostate cancer. Anticancer Res 1994;14: 2785-2790.

35 Petersen I, Klein F: HPV in non-gynecological tumors. Pathologe 2008;29:118-122.

$36 \mathrm{Tu}$ H, Jacobs SC, Mergner WJ, Kyprianou N: Rare incidence of human papillomavirus types 16 and 18 in primary and metastatic human prostate cancer. Urology 1994;44: 726-731.

37 Wideroff L, Schottenfeld D, Carey TE, Beals T, Fu G, Sakr W, Sarkar F, Schork A, Grossman HB, Shaw MW: Human papillomavirus DNA in malignant and hyperplastic prostate tissue of black and white males. Prostate 1996;28:117-123. 